\title{
Early Life Adverse Environmental Exposures Increase the Risk of Uterine Fibroid Development: Role of Epigenetic Regulation
}

\section{OPEN ACCESS}

Edited by:

Maged Costantine, University of Texas Medical Branch,

USA

Reviewed by:

Monica Longo,

The University of Texas Health

Science Center at Houston, USA

Judith Ann Smith,

The University of Texas Medical

School at Houston, USA

Sherif Abdel-Rahman,

University of Texas Medical Branch,

USA

*Correspondence: Qiwei Yang qyang@gru.edu

Specialty section: This article was submitted to Obstetric and Pediatric Pharmacology,

a section of the journa

Frontiers in Pharmacology

Received: 03 November 2015

Accepted: 12 February 2016

Published: 01 March 2016

Citation:

Yang Q, Diamond MP and Al-Hendy A (2016) Early Life Adverse Environmental Exposures Increase the Risk of Uterine Fibroid Development: Role of Epigenetic Regulation. Front. Pharmacol. 7:40. doi: 10.3389/fphar.2016.00040

\section{Qiwei Yang *, Michael P. Diamond and Ayman Al-Hendy}

Division of Translation Research, Department of Obstetrics and Gynecology, Medical College of Georgia, Augusta University, Augusta, GA, USA

Uterine Fibroids [UF(s), AKA: leiomyoma] are the most important benign neoplastic threat to women's health. They are the most common cause of hysterectomy imposing untold personal consequences and 100s of billions of healthcare dollars, worldwide. Currently, there is no long term effective FDA-approved medical treatment available, and surgery is the mainstay. The etiology of UFs is not fully understood. In this regard, we and others have recently reported that somatic mutations in the gene encoding the transcriptional mediator subunit Med12 are found to occur at a high frequency ( $85 \%)$ in UFs. UFs likely originate when a Med12 mutation occurs in a myometrial stem cell converting it into a tumor-forming stem cell leading to a clonal fibroid lesion. Although the molecular attributes underlying the mechanistic formation of UFs is largely unknown, a growing body of literature implicates unfavorable early life environmental exposures as potentially important contributors. Early life exposure to EDCs during sensitive windows of development can reprogram normal physiological responses and alter disease susceptibility later in life. Neonatal exposure to the EDCs such as diethylstilbestrol (DES) and genistein during reproductive tract development has been shown to increase the incidence, multiplicity and overall size of UFs in the Eker rat model, concomitantly reprogramming estrogen-responsive gene expression. Importantly, EDC exposure represses enhancer of zeste 2 (EZH2) and reduces levels of histone 3 lysine 27 trimethylation (H3K27me3) repressive mark through Estrogen receptor/Phosphatidylinositide 3-kinases/Protein kinase B non-genomic signaling in the developing uterus. Considering the fact that distinct Mediator Complex Subunit 12 (Med12) mutations are detected in different fibroid lesions in the same uterus, the emergence of each Med12 mutation is likely an independent event in an altered myometrial stem cell. It is therefore possible that a chronic reduction in DNA repair capacity eventually causes the emergence of mutations such as Med12 in myometrial stem cells converting them into fibroid tumor-forming stem cells, and thereby leads to the development of UFs. Advancing our understanding of the mechanistic role epigenetic regulation of stem cells plays in mediating risk and tumorigenesis will help in pointing the way toward the development of novel therapeutic options.

Keywords: fibroid, endocrine disrupting compounds, histone modification, polycomb repressive complex, Trithorax group, developmental reprogramming 


\section{INTRODUCTION}

Exposure to environmental toxicants and toxins causes epigenetic changes that play a role in the development of disease (Cook et al., 2005; Walker and Ho, 2012; Yang et al., 2015b). Identifying changes in epigenomic marks (e.g., DNA methylation, histone modifications, non-coding RNAs) in affected tissues/cells is not always feasible in humans. Herein lies one of the challenges in making a direct connection between exposure-induced epigenetic changes and health outcomes in human populations. UFs, also known as uterine leiomyomas, are the most common pelvic tumors, occurring in nearly $70 \%$ of all reproductive-aged women (Al-Hendy and Salama, 2006; Bulun, 2013). It is the leading indication for hysterectomy with a conservative economic burden of about $\$ 34.4$ billion/year in the US alone (Cardozo et al., 2012). These UFs cause severe symptoms such as heavy, irregular, and prolonged menstrual bleeding, anemia, pelvic pain, bowel and bladder dysfunction, infertility, recurrent abortion, and many obstetric complications such as preterm labor, obstructed labor necessitating cesarean section, fetal malpresentation, and fetal anomalies, as well as postpartum hemorrhaging (Sabry and Al-Hendy, 2012). These morbidities exert a tremendous toll on an individual's overall health and well-being, impacting the quality of life of women of all ethnicities. Understanding mechanisms which regulate normal and aberrant myometrial cell function is paramount in the management of UFs. Therefore, development of effective, safe and inexpensive approach for the management of UFs is highly needed to improve the quality of life among those affected by UFs, but also in consideration of the significant impact UFs have in the context of public health (Sabry and Al-Hendy, 2012).

\section{THE ROLE OF ESTROGEN IN NON-GENOMIC AND GENOMIC SIGNALING OF UFs}

A striking feature of UFs is their dependency on the ovarian steroids estrogen and progesterone (Bulun, 2013). A number of experimental data suggests that estrogen stimulates the growth of UFs through ER $\alpha$. The primary roles of estrogen and its' receptor $\alpha$ in UFs growth are permissive in that they enable tissue to respond to progesterone by inducing expression of the progesterone receptor (Ishikawa et al., 2010).

The biological effects of $17 \beta$-estradiol are mediated by two isoforms of the ERs (ER $\alpha$ and ER $\beta$ ). Hormone-activated ERs

Abbreviations: AKT, Protein kinase B; Ash2L, absent, small, or homeotic-like; BMI1, B-B-lymphoma Mo-MLV insertion region 1 homolog; BPA, Bisphenol A; BTIC, breast tumor initiating cells; CBP, CREB binding protein; CBX, chromobox homolog; DES, diethylstilbestrol; Dpy30, dosage compensation-related protein 30; EDCs, endocrine disrupting compounds; EED, embryonic ectoderm development; ERs, Estrogen receptors; EZH2, enhancer of zeste 2; HMG 14, high mobility group protein 14; MAPK, mitogen-activated protein kinases; Med12, Mediator Complex Subunit 12; MET, Mesenchymal epithelial transition factor; MLL, mixedlineage leukemia protein; P300, E1A binding protein P300; PcG, Polycomb group; PHC, polyhomeotic homolog; PI3K, phosphatidylinositide 3-kinases; RbBP5, retinoblastoma binding protein 5 ; RING1A or RING1B, ring finger $1 \mathrm{~A}$ or $1 \mathrm{~B}$; SUZ12, Suppressor of zeste 12; TrxG, trithorax group; UFs, Uterine fibroids; WDR5, WD40 repeat domain 5 . form dimers. Since the two forms are coexpressed in many cell types, the receptors may form $\mathrm{ER} \alpha(\alpha \alpha)$ or $\mathrm{ER} \beta(\beta \beta)$ homodimers or $E R \alpha \beta(\alpha \beta)$ heterodimers. Although ERs are widely expressed in different tissues types, some notable differences in their expression patterns occur. For instance, the ER $\alpha$ is found in endometrium, ovarian stromal cells, and breast cancer cells. ERs mediate the effects of $17 \beta$-estradiol under physiologic and pathologic conditions. ERs trigger $17 \beta$-estradiol-sensitive gene transcription by binding to specific estrogen response elements (i.e., genomic mechanism) (Hewitt et al., 2003; Gielen et al., 2007; Winuthayanon et al., 2014). In the absence of the estrogen hormone, ERs are largely located in the cytosol. The estrogen binds to the receptor, triggering a cascade of events, starting with the migration of the receptor from the cytosol into the nucleus; dimerization of the receptor; and subsequent binding of the receptor dimer to specific sequences of DNA known as estrogen response elements. The DNA/receptor complex then recruits other proteins that are responsible for transcriptional activation, which eventually alters target gene expression. ERs are also found within the cell nucleus, and both ER subtypes have a DNA-binding domain and can function as transcription factors to regulate gene expression (Burns and Korach, 2012).

Some ERs can be rapidly activated to downstream kinase cascades by exposure of the cells to estrogen (i.e., nongenomic mechanism; Bjornstrom and Sjoberg, 2002, 2005; Wong et al., 2002; Hofmeister et al., 2012). These so-called "non-genomic" effects are independent of gene transcription or protein synthesis and involve steroid-induced modulation of cytoplasmic or cell membrane-bound regulatory proteins. Estrogen can modulate regulatory cascades, such as MAPK, PI3K, and tyrosine kinases through non-transcriptional mechanisms. Furthermore, steroid hormone receptor modulation of cell membrane-associated molecules, such as ion channels and G-protein-coupled receptors, e.g., GPR30 has been shown in diverse tissues (Kelly et al., 2003; Prossnitz and Arterburn, 2015).

Both ER-evoked genomic and non-genomic effects originate from a unique signaling network (Bjornstrom and Sjoberg, 2005). A growing amount of evidence suggests that non-transcriptional signaling plays a pivotal role in the estrogen effect, which has clinical relevance, particularly in the development of UFs. Fibroids are common estrogen-dependent uterine tumors that cause significant morbidity for women and inflict a substantial economic impact on the US health delivery system (Al-Hendy and Salama, 2006). Our in vivo data in a mouse model demonstrates the ability of an adenovirus-expressing dominantnegative ER to arrest fibroid growth (Hassan et al., 2010). Taken together, cellular activities of estrogen and EDCs are the result of a combination of non-genomic and genomic actions via membrane and nuclear ERs-mediated signaling pathways.

\section{EPIGENETIC MODIFICATIONS: PcG PROTEINS AND TrXG PROTEINS}

Epigenetic regulation is a dynamic process, which integrates environmental changes and enables cellular plasticity. As a result, it is involved in various pathologies related to environmental 
exposure to toxins. Proteins that carry out these epigenetic modifications are classified as "writers", "readers", and "erasers" (Figure 1). Epigenetic writers catalyze the addition of chemical groups onto either histone tails or onto the DNA itself (Cosgrove, 2012). These modifications are known as epigenetic marks (Vermeulen et al., 2010; Yun et al., 2011). Among them, PcG and TrxG proteins function as crucial epigenetic "writers" that regulate developmental gene expression in a variety of tissues and organs (Figure 2; Ringrose and Paro, 2007; Schuettengruber et al., 2007).

Polycomb group proteins form multimeric complexes that exert their functions by modifying chromatin structure and by regulating the deposition and recognition of multiple posttranslational histone modifications (Morey and Helin, 2010). Two major PcG protein complexes have been described. The first complex, named polycomb repressive complex 1 (PRC1) is composed of four submits as shown in Figure 2. The second complex PRC2 consists primarily of EZH2, which is the catalytic core protein, EED, and SUZ12 (Figure 2). PRC2 methylates $\mathrm{H} 3 \mathrm{~K} 27$ via its EZH2 subunit. This modification, in turn, provides a binding site for the chromodomaincontaining Pc subunit of PRC1, which subsequently leads to ubiquitination of H2AK119 via its Ring1a/1b subunit (Wang et al., 2004; Lehmann et al., 2012; Figure 2). In recent years, these proteins have raised considerable interest, due to their regulatory mechanisms and for the variety of key roles they play in normal cellular and disease processes (Villa et al., 2007; Pasini et al., 2010; Ntziachristos et al., 2012; Mozzetta et al., 2014; Serresi et al., 2016). For instance, EZH2 regulates chromatin structure and chromosome architecture at their target loci (Table 1) through canonical and non-canonical activity (Figure 3).
Trithorax group proteins also function in multi-subunit complexes (Figure 2), confer heritable memory by sustaining active gene expression states, but they antagonize the function of the PcG (Schuettengruber et al., 2007, 2011; Steffen and Ringrose, 2014). For example, H3K4 trimethylation inhibits PRC2-mediated H3K27 trimethylation (Schmitges et al., 2011).

\section{EPIGENETIC TARGETS IN RESPONSE TO ENVIRONMENTAL FACTORS IN SOME TISSUES}

The process of developmental programming exhibits a high degree of epigenetic plasticity, which is modifiable by intrinsic and extrinsic factors (Walker and Ho, 2012). However, when the in utero environment is suboptimal, permanent developmental reprogramming of the epigenetic targets could take place. Adverse environmental exposures during development can alter susceptibility later in life to adult diseases, including UFs (Cook et al., 2005, 2007; Greathouse et al., 2012). Increasing evidence suggests that early exposure to EDCs induces epigenetic changes in context to epigenetic regulated target genes in some tissues (Cook et al., 2005; Wong et al., 2015). For instance, neonatal exposure of CD-1 mice to EDCs such as DES (Walker and Ho, 2012; Gibson and Saunders, 2014), induces uterine adenocarcinoma in aging animals, concomitantly inducing hypomethylation of nucleosome binding protein 1 $(N s b p 1)$ promoter CpG Island (CGI) in the uteri which leads to persistent overexpression throughout life. Since the Nsbp1 encodes a nuclear protein similar to the HMG 14, this protein may alter the gene expression pattern in utero, in

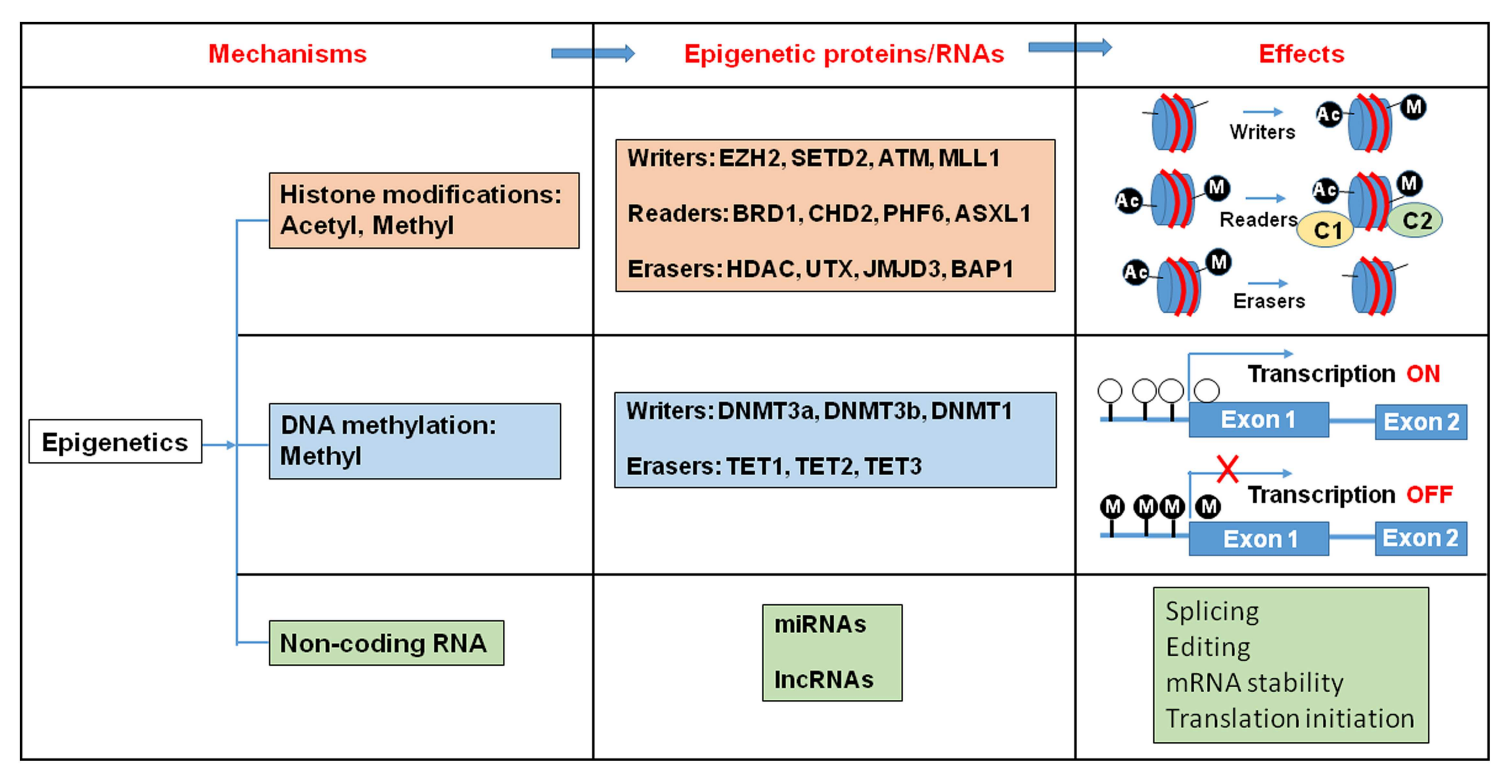

FIGURE 1 | Histone modification, DNA methylation, and non-coding RNA alter gene expression pattern. Epigenetic writers catalyze the chemical modifications of amino acids on histones or the cytosine of DNA. Epigenetic erasers catalyze the removal of these modifications and epigenetic readers recognize the modifications and recruit large macromolecular complexes to the chromatin template. Ac, Acetyl; M, Metyl; C, protein complex. 


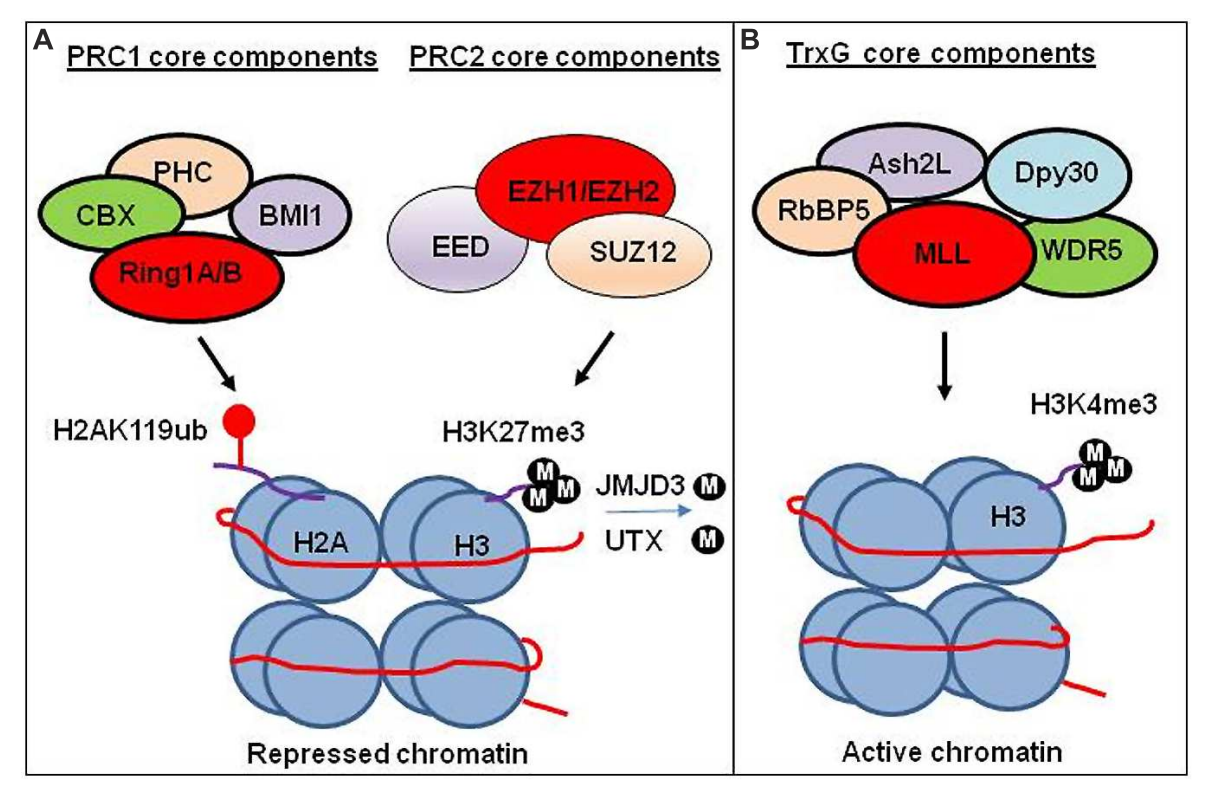

FIGURE 2 | Transcriptional regulation by PRC1, PRC2, and TrxG chromatin complex. (A) Transcriptional regulation by PRC1 and PRC2 complex. PRC1 ubiquitinate H2A at lysine 119 (H2AK119ub). PRC2 trimethylates lysine 27 on histone 3 (H3K27me3). Experimental study suggests that H3K27me3 generated by PRC2 facilitates compaction of chromatin leading to the repression of gene expression. The CBX subunit of the PRC1 recognizes H3K27me3, and subsequently RING1A/B subunits of the PRC1 ubiquitinate H2AK119 to facilitate the maintenance of the repressed state. H3K27 demethylases JMJD3 and UTX demethylate methylated H3K27. (B) Transcriptional regulation by TrxG complex. TrxG trimethylates histone 3 lysine (H3K4me3) leading to activate gene expression.

response to early life EDC exposure leading to an increased risk of uterine cancer in adulthood (Tang et al., 2008). In rat mammary gland, prenatal exposure to BPA, another EDC, alters the epigenome and increases the propensity to neoplastic development. Accordingly, BPA exposure led to higher levels of MLL mediated epigenetic mark $\mathrm{H} 3 \mathrm{~K} 4$ trimethylation at the transcriptional initiation site of the alpha-lactalbumin gene, concurrently enhancing mRNA expression of this gene (Dhimolea et al., 2014). The protein encoded by this gene plays an important role in galactose metabolism. In addition, using a rat model for developmental reprogramming of susceptibility to prostate carcinogenesis (Yean Wong et al., 2015), neonatal exposure to BPA significantly upregulated ( $>100$-fold) the expression of $S c g b 2 a 1$ in the prostate of adult rats via $\mathrm{H} 3$ lysine 9 acetylation. Importantly, Secretoglobin, Family 2A, Member 1 (Scgb2a1) encodes a component of prostatein, a major androgen-binding protein secreted by rat prostate, and hence suggests potential implications for cancer risk and response to chemotherapeutics associated with prostatein binding (Wong et al., 2015).

\section{ANIMAL MODEL FOR DEVELOPMENTAL REPROGRAMMING OF SUSCEPTIBILITY TO UF PATHOGENESIS}

Although there are several UF developmental models available (Hassan et al., 2009; Friel et al., 2010; Prizant et al., 2013; Mas et al., 2015), the best experimental animal model for studying UFs in response to early life adverse environmental exposure is the
Eker rat model (Cook et al., 2005; Walker and Ho, 2012). Eker rats carry a germ-line mutation in the tuberous sclerosis complex-2 (Tsc2) tumor suppressor gene (Cook and Walker, 2004). In this Eker rodent model, the high spontaneous incidence of smooth muscle tumors of the uterus provides a unique opportunity to study the molecular mechanisms underlying the development of these clinically important neoplasms (Everitt et al., 1995). Using this model, Dr. Walker's group demonstrated that early life exposure to EDCs including DES or genistein, a natural isoflavone phytoestrogen found in soybeans, increased tumor penetrance (from $65 \%$ to $>90 \%$ ), tumor multiplicity and overall size (Cook et al., 2005; Greathouse et al., 2012). This increased penetrance induced by early life environmental exposure to EDCs is associated with the reprogramming of estrogen-responsive genes, which become hyper-responsive to the estrogen hormone and promote the development of hormone-dependent UFs (Greathouse et al., 2008; Walker and Ho, 2012).

\section{ROLE OF EPIGENETIC "WRITERS" IN UF DEVELOPMENT}

Estrogen triggering genomic signaling in context to epigenetic "writers" has recently been identified. Bhan et al. (2014) demonstrate that EZH2 is transcriptionally induced by estradiol in cultured breast cancer cells and in the mammary glands of ovariectomized rats. Similar to estradiol, DESinduced EZH2 expression is coordinated by ERs, MLLs and $\mathrm{CBP} / \mathrm{P} 300$. These studies suggest that EZH2 is potentially dysregulated upon exposure to EDCs, and provides a direct 
TABLE 1 | List of EZH2-regulated genes.

\begin{tabular}{|c|c|c|c|c|}
\hline Genes & Tumor type & Activation/repression & Journal & year \\
\hline INK/ARF & Non-specific & Repression & EMBO J. & 2003 \\
\hline RAD51 & Breast & Repression & Neoplasia; Cancer Cell & $2005 ; 2011$ \\
\hline ADRB2 & Prostate & Repression & Cancer Cell & 2007 \\
\hline BMPR1B & Glioma & Repression & Cancer Cell & 2008 \\
\hline $\mathrm{CDH} 1$ & Prostate & Repression & Oncogene & 2008 \\
\hline DKK1 & Lung & Repression & Cancer Res. & 2009 \\
\hline DARB2 & Prostate & Repression & Nat. Med. & 2010 \\
\hline VASH1 & Ovarian & Repression & Cancer Cell & 2010 \\
\hline CASZ1 & Neuroblastoma & Repression & Cancer Res. & 2011 \\
\hline CLU & Neuroblastoma & Repression & Cancer Res. & 2011 \\
\hline RUNX3 & Neuroblastoma & Repression & Cancer Res. & 2011 \\
\hline NGFR & Neuroblastoma & Repression & Cancer Res. & 2011 \\
\hline $\mathrm{HOX}$ & Mantle cell lymphoma & Repression & Epigenetics & 2013 \\
\hline ITGA2 & Colon & Repression & PloS ONE & 2014 \\
\hline RUNX1 & Prostate & Repression & Oncotarget & 2014 \\
\hline MDR & Glioblastoma & Repression & Int. J. Clin. Exp. Pathol. & 2014 \\
\hline MRP & Glioblastoma & Repression & Int. J. Clin. Exp. Pathol. & 2014 \\
\hline BCRP & Glioblastoma & Repression & Int. J. Clin. Exp. Pathol. & 2014 \\
\hline CDKN2A & Hepatocellar carcinoma & Repression & Mol. Cancer Res. & 2014 \\
\hline $\mathrm{E} 2 \mathrm{~F} 1$ & Hepatocellar carcinoma & Repression & Mol. Cancer Res. & 2014 \\
\hline Notch2 & Hepatocellar carcinoma & Repression & Mol. Cancer Res. & 2014 \\
\hline TP53 & Hepatocellar carcinoma & Repression & Mol. Cancer Res. & 2014 \\
\hline E-cadherin & Renal & Repression & BJU Int. & 2014 \\
\hline DCK & Melanoma & Repression & Nat. Commun. & 2015 \\
\hline AMD1 & Melanoma & Repression & Nat. Commun. & 2015 \\
\hline WDR19 & Melanoma & Repression & Nat. Commun. & 2015 \\
\hline c-myc & Breast & Activation & Mol. Cell Biol. & 2007 \\
\hline cyclinD1 & Breast & Activation & Mol. Cell Biol. & 2007 \\
\hline TNF & Breast & Activation & Molecular Cell & 2011 \\
\hline IL6 & Breast & Activation & Molecular Cell & 2011 \\
\hline IL8 & Breast & Activation & Molecular Cell & 2011 \\
\hline$A R$ & Prostate & Activation & Science & 2012 \\
\hline
\end{tabular}

EZH2 is involved in regulation of gene expression through repressed or activated mechanism.

link between EDC-induced nuclear hormone receptor signaling and modulation of the epigenetic machinery (Bhan et al., 2014).

Until recently, little information has been available about the role of PcG/TrxG proteins in the development UFs. However, Dr. Walker's group reported that DES is capable of binding to membrane-associated ER to activate non-genomic ER signaling, activating PI3K signaling and the kinase AKT. Subsequently Phosphorylation of serine 21 of EZH2 by AKT inactivates EZH2 leading to reduced levels of the repressive trimethylation of $\mathrm{H} 3 \mathrm{~K} 27$ in the developing uterus (Bredfeldt et al., 2010). A further study indicated that yet another environmental estrogen, genistein, also induced PI3K/AKT non-genomic ER signaling to the histone EZH2 (Greathouse et al., 2012). These studies demonstrate the importance of the interplay between non-genomic signaling and epigenetic mechanisms in response to early life environmental exposure to estrogen that may contribute to an increased risk of UF development.

\section{DNA DAMAGE REPAIR IN STEM CELLS}

Accumulating evidence demonstrates that environmental chemicals or their reactive intermediates can react with DNA to modify DNA bases leading to DNA damage (Linder, 2012; Moller et al., 2013). Exposures can act through an epigenetic mechanism by which DNA damage repair is altered (Langie et al., 2013). Currently, Med12 somatic mutation is the most widely detected DNA mutation in human fibroid lesions. We and others have detected a single nucleotide Med12 mutations in up to $85 \%$ of sporadic fibroid lesions (Makinen et al., 2011a,b; Markowski et al., 2012; McGuire et al., 2012; Halder et al., 2014). Interestingly, distinct Med12 mutations are detected in different fibroid lesions in the same uterus (Makinen et al., 2011b). This strongly suggests that the emergence of each Med12 mutation is an independent event in an altered myometrial stem cells. It is possible that some risk factors attenuate key DNA damage repair gene function leading to reduced myometrial DNA repair capacity. This reduction in the 


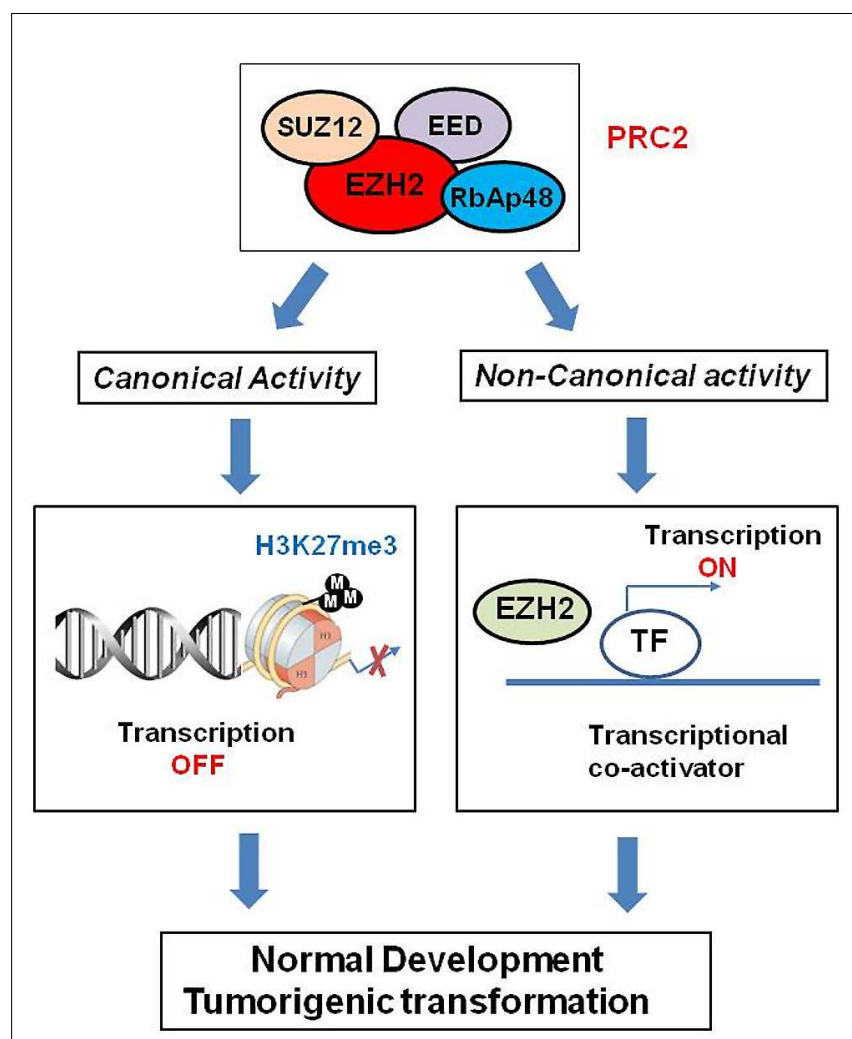

FIGURE 3 | Role of EZH2 in genomic signaling through canonical and non-canonical activity. EZH2 confers long-term, heritable memory by sustaining silent gene expression states. In addition to its role as epigenetic modifier, EZH2 also works as transcriptional co-activators through non-canonical signaling pathway.

DNA repair capacity may eventually cause the emergence of mutations such as Med12 in myometrial stem cells converting them into fibroid tumor-forming stem cells; and thereby, leading to the development of UFs (Figure 4). In a mouse model that conditionally expresses a Med12 missense variant (c. 131G > A), it has been demonstrated that this alteration alone promotes fibroid formation and drives genomic instability (Mittal et al., 2015).

A comparative analysis of dysfunctional DNA repair capacity in stem cells from fibroid tissues or at-risk myometrium with fibroid versus stem cells from normal myometrium has not yet been conducted. However, Chang et al. (2011) reported that BTICs exhibited increased EZH2 expression which was linked to decreased expression of key DNA repair gene RAD51. Therefore, accumulation of recurrent Raf-1 proto-oncogene, serine/threonine Kinase (RAF1) gene amplification in BTICs occurred, which activates p-ERK$\beta$-catenin signaling to promote BTIC expansion (Chang et al., 2011). It has been shown that both human myometrial and UF tissues contain side population (SP) cells with progenitor/stem cell properties (Ono et al., 2007, 2012, 2013; Mas et al., 2012). We recently isolated human surface markerspecific myometrial and fibroid stem cells. Using Stro-1/CD44

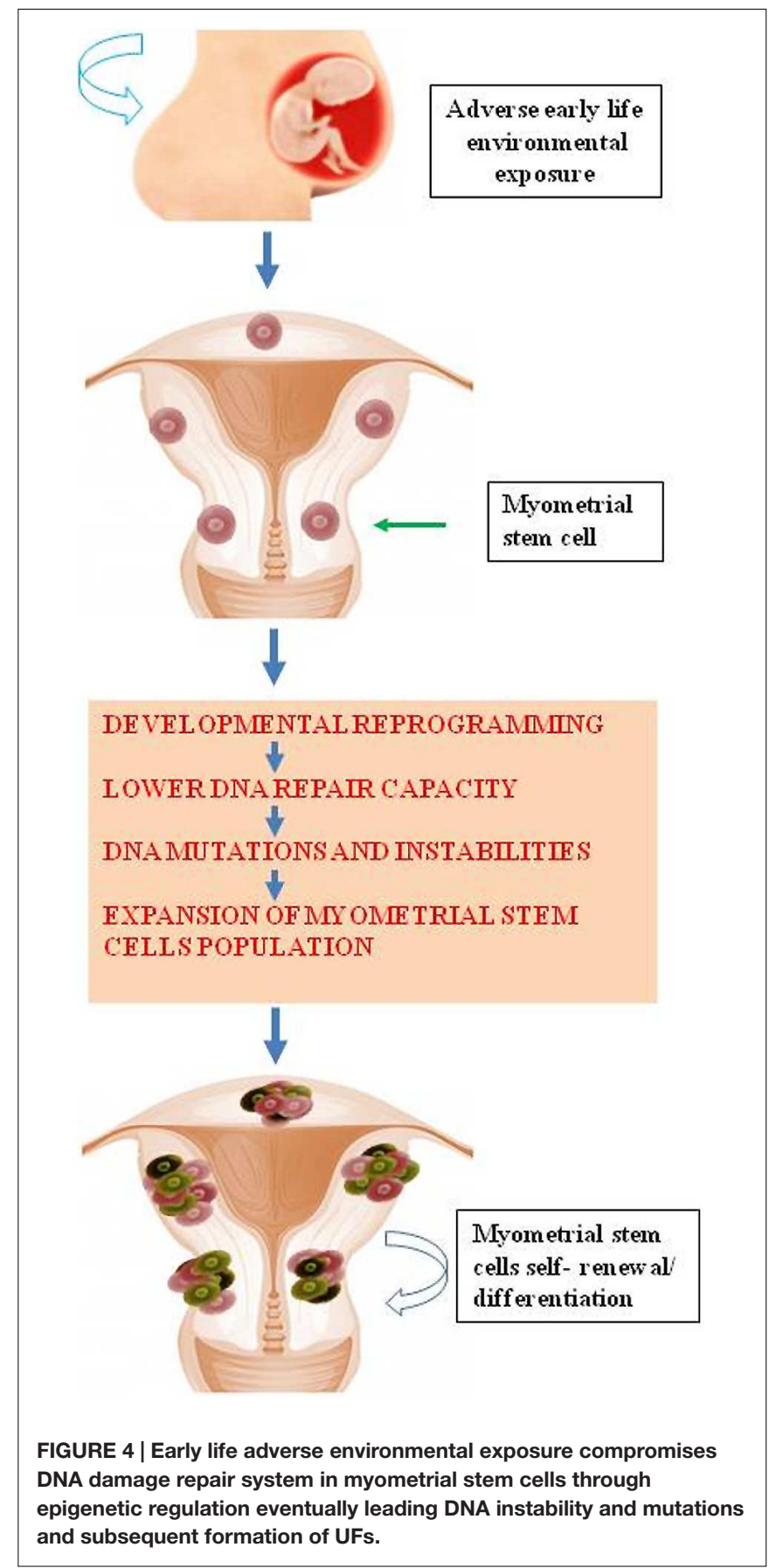

surface markers, we were able to isolate stem cells from adjacent myometrium and human fibroid tissues using the magnetic beads approach (Mas et al., 2015). In vitro Stro$1^{+} / \mathrm{CD} 44^{+}$myometrial cells exhibit the ability to differentiate into adipocytes, osteocytes, and chondrocytes with the functional capacity to form fibroid-like lesions in a xenotransplantation mouse model. In the future, we will compare the DNA repair capacity of Stro- $1^{+} / \mathrm{CD} 44^{+}$myometrial stem cells from normal human myometrium versus at-risk myometrium tissues or fibroids. 


\section{CELL-DERIVED EXOSOMES: ROLES IN TUMOR DEVELOPMENT AND PROGRESSION}

Emerging evidence consistently demonstrates that exosomal miRNAs can be reprogrammed by environmental factors (Goustard-Langelier et al., 2013; Shah et al., 2016). Exosome are cell-derived small sized vesicles (40-150 nm), present in many biological fluids (Pan et al., 1985; Simons and Raposo, 2009). Exosomes are either released from the cells when multivesicular bodies fuse with plasma membrane or released directly from the plasma membrane. Emerging evidence indicates that exosomes contain a range of biological molecules, including mRNA, microRNA, long non-coding RNAs, proteins, lipids, molecular chaperones, and signaling molecules (Skog et al., 2008), as well as involvement in many biological events including cancer progression (Kogure et al., 2011; Luga et al., 2012). Importantly, the molecular signatures of exosomes are specific to each tissue type, providing an alternative option for clinical applications (Nawaz et al., 2014).

Exosomes exhibit fundamental paracrine mechanisms that mediate cell-to-cell communication and play a role in the transfer of messages from one cell to another (Simons and Raposo, 2009; O'Brien et al., 2013). Exosomes are important players in the regulation of physiological as well as pathological processes in our body - depending on their content, they can induce activation, proliferation, differentiation, or apoptosis of the recipient cells (Roma-Rodrigues et al., 2014; Ung et al., 2014). In cancer, this cell-to-cell communication leads to increased proliferation, motility, induction of invasive properties of the recipient cells, as well as conferring drug resistance (Kahlert and Kalluri, 2013).

Although the role of exosomes in tumor development is not well understood, some studies have highlighted a possible role in tumor development and progression. Exosomes with a specific surface protein (glypican-1) were found to be detected in the serum of patients with pancreatic cancer, distinguishing healthy subjects from those with benign pancreatic disease (Melo et al., 2015). Melanome exosomes educate bone marrow progenitor cells toward a pro-metastatic phenotype via MET, and exosome-mediated transfer of the oncoprotein. MET functions as a key regulator of bone marrow education, mobilization, and metastatic progression (Peinado et al., 2012). The exosomes from normal and abnormal cells differ in their cargo content, and potentially in their functions. For instance, breast cancer exosomes perform cell-independent miRNA biogenesis and alter the transcriptome of receipt cells in a Dicer-dependent manner (Melo et al., 2014).

Uterine Fibroids are thought to be monoclonal tumors arising from the myometrium, and tumor stem cells are considered to play pivotal roles in the tumorigenesis of UFs. It is possible that cell-to-cell interaction between myometrial stem cells and differentiation cells is involved in the development of UFs. Although the role of myometrial stem cell-derived exosomes is unknown, increasing, studies have suggested that stem cell-derived exosomes containing important effectors of Wnt (Luga et al., 2012), Hedgehog (Gradilla et al., 2014), and $\beta$-catenin (Chairoungdua et al., 2010), may play a potential role in maintaining stem cell characteristics. Cancer stem cell-derived exosomes contain distinct biomolecules as compared to exosomes derived from normal stem cells indicating the important role of exosomal miRNA content from cancer stem cells in cancer progression and development. For instance, gastric cancer tissue-derived mesenchymal stem cells favor gastric cancer progression by transferring exosomal miRNAs to gastric cancer cells and promote their proliferation and migration (Wang et al., 2014). Similarly, glioma-associated stem cells produce substantial amounts of exosomes which leads to sustained malignant properties of both glioma cells and glioma stem cells. Moreover, a recent study has shown that exosomes from bone marrow-derived mesenchymal stem cells transport tumor regulatory miRNAs, anti-apoptotic proteins, and metabolites that promote breast tumor growth (Vallabhaneni et al., 2015). These studies suggest that stem cell-derived exosomes contain important molecules that promote tumor progression.

The importance of stem cell-derived miRNAs in response to environmental factors has recently been identified (GoustardLangelier et al., 2013; Shah et al., 2016). Shah et al. (2016) determined the effects of the chemoprotective fish oil/pectin diet on miRNAs in colonic stem cells obtained from Lgr5EGFP-IRES-creER knock-in mice. They demonstrated that 26 miRNAs were differentially expressed in Lgr5 (high) stem cells as compared to Lgr5 (negative) differentiated cells. Fish oil/pectin treatment up-regulated miR-19b, miR-26b and miR203 expression as compared to corn oil plus cellulose (CCA) specifically in Lgr5 (high) cells. They further demonstrated that only miR-19b and its indirect target PTK2B were modulated by the fish oil/pectin diet in Lgr5 (negative) cells. In addition, rat neural stem cells/neural progenitors (NSC) proliferation and differentiation were dually altered by the in utero polyunsaturated fatty acid supply, along with marked alterations in miRNA expression (Goustard-Langelier et al., 2013). Although the role of exosomes in the pathogenesis of UFs is unknown, we recently isolated myometrium stem cells from adult uteri early life exposed to DES. These cells will serve as a tool in determining how early life environmental exposure alters stem cell derived exosomal cargo and thereby leads to an increased risk of UF pathogenesis.

\section{CONCLUDING REMARKS}

Currently, there is a remarkable lack of knowledge regarding the involvement of chromatin assembly in the process by which adverse environmental exposures increase the overall risk of UF development. The precise mechanism underlying EDC-dependent effects on myometrial cell physiology are not adequately understood. Accordingly, in response to EDC administration, no single PcG or TrxG-target genes have been discovered in myometrium tissues as well as in myometrial stem cells (Yang et al., 2015a). In addition to EZH2 "writer", many other epigenetic proteins that play a role in UF development, need to be investigated. High throughput epigenetic analysis such as ChIP-seq are needed to determine locus specific and/or genome-wide epigenetic modifications in myometrial 
stem cells and tissues. A better understanding of these changes in myometrial stem cells will lead to the mechanistic plausibility as to the role of epigenetic regulation in mediating risk and tumorigenesis and the development of new stem cell-directed therapies for patients with UFs.

\section{AUTHOR CONTRIBUTIONS}

QY and AA, conception of the manuscript; QY, drafted the manuscript; $\mathrm{QY}, \mathrm{MD}$, and $\mathrm{AA}$, revised the manuscript. All authors approved the revised version of the manuscript.

\section{REFERENCES}

Al-Hendy, A., and Salama, S. (2006). Gene therapy and uterine leiomyoma: a review. Hum. Reprod. Update 12, 385-400. doi: 10.1093/humupd/dml015

Bhan, A., Hussain, I., Ansari, K. I., Bobzean, S. A., Perrotti, L. I., and Mandal, S. S. (2014). Histone methyltransferase EZH2 is transcriptionally induced by estradiol as well as estrogenic endocrine disruptors bisphenol-A and diethylstilbestrol. J. Mol. Biol. 426, 3426-3441. doi: 10.1016/j.jmb.2014.07.025

Bjornstrom, L., and Sjoberg, M. (2002). Signal transducers and activators of transcription as downstream targets of nongenomic estrogen receptor actions. Mol. Endocrinol. 16, 2202-2214. doi: 10.1210/me.2002-0072

Bjornstrom, L., and Sjoberg, M. (2005). Mechanisms of estrogen receptor signaling: convergence of genomic and nongenomic actions on target genes. Mol. Endocrinol. 19, 833-842. doi: 10.1210/me.2004-0486

Bredfeldt, T. G., Greathouse, K. L., Safe, S. H., Hung, M. C., Bedford, M. T., and Walker, C. L. (2010). Xenoestrogen-induced regulation of EZH2 and histone methylation via estrogen receptor signaling to PI3K/AKT. Mol. Endocrinol. 24, 993-1006. doi: 10.1210/me.2009-0438

Bulun, S. E. (2013). Uterine fibroids. N. Engl. J. Med. 369, 1344-1355. doi: 10.1056/NEJMra1209993

Burns, K. A., and Korach, K. S. (2012). Estrogen receptors and human disease: an update. Arch. Toxicol. 86, 1491-1504. doi: 10.1007/s00204-012-0868-5

Cardozo, E. R., Clark, A. D., Banks, N. K., Henne, M. B., Stegmann, B. J., and Segars, J. H. (2012). The estimated annual cost of uterine leiomyomata in the United States. Am. J. Obstet. Gynecol. 206, e211-e219. doi: 10.1016/j.ajog. 2011.12.002

Chairoungdua, A., Smith, D. L., Pochard, P., Hull, M., and Caplan, M. J. (2010). Exosome release of beta-catenin: a novel mechanism that antagonizes Wnt signaling. J. Cell Biol. 190, 1079-1091. doi: 10.1083/jcb.201002049

Chang, C. J., Yang, J. Y., Xia, W., Chen, C. T., Xie, X., Chao, C. H., et al. (2011). EZH2 promotes expansion of breast tumor initiating cells through activation of RAF1-beta-catenin signaling. Cancer Cell 19, 86-100. doi: 10.1016/j.ccr.2010.10.035

Cook, J. D., Davis, B. J., Cai, S. L., Barrett, J. C., Conti, C. J., and Walker, C. L. (2005). Interaction between genetic susceptibility and early-life environmental exposure determines tumor-suppressor-gene penetrance. Proc. Natl. Acad. Sci. U.S.A. 102, 8644-8649. doi: 10.1073/pnas.0503218102

Cook, J. D., Davis, B. J., Goewey, J. A., Berry, T. D., and Walker, C. L. (2007). Identification of a sensitive period for developmental programming that increases risk for uterine leiomyoma in Eker rats. Reprod. Sci. 14, 121-136. doi: $10.1177 / 1933719106298401$

Cook, J. D., and Walker, C. L. (2004). The Eker rat: establishing a genetic paradigm linking renal cell carcinoma and uterine leiomyoma. Curr. Mol. Med. 4, 813824. doi: $10.2174 / 1566524043359656$

Cosgrove, M. S. (2012). Writers and readers: deconvoluting the harmonic complexity of the histone code. Nat. Struct. Mol. Biol. 19, 739-740. doi: 10.1038/nsmb. 2350

Dhimolea, E., Wadia, P. R., Murray, T. J., Settles, M. L., Treitman, J. D., Sonnenschein, C., et al. (2014). Prenatal exposure to BPA alters the epigenome of the rat mammary gland and increases the propensity to neoplastic development. PLOS ONE 9:e99800. doi: 10.1371/journal.pone. 0099800

\section{FUNDING}

This work was supported in part by an Augusta University Startup package, the National Institutes of Health grant HD04622811 (to AA), and the Augusta University Intramural Grants Program (QY).

\section{ACKNOWLEDGMENT}

We would like to thank Walidah Walker, MPH for editing this manuscript.

Everitt, J. I., Wolf, D. C., Howe, S. R., Goldsworthy, T. L., and Walker, C. (1995). Rodent model of reproductive tract leiomyomata. Clinical and pathological features. Am. J. Pathol. 146, 1556-1567.

Friel, A. M., Growdon, W. B., McCann, C. K., Olawaiye, A. B., Munro, E. G., Schorge, J. O., et al. (2010). Mouse models of uterine corpus tumors: clinical significance and utility. Front. Biosci. (Elite Ed.) 2:882-905. doi: 10.2741/E149

Gibson, D. A., and Saunders, P. T. (2014). Endocrine disruption of oestrogen action and female reproductive tract cancers. Endocr. Relat. Cancer 21, T13-T31. doi: 10.1530/ERC-13-0342

Gielen, S. C., Santegoets, L. A., Kuhne, L. C., Van Ijcken, W. F., Boers-Sijmons, B., Hanifi-Moghaddam, P., et al. (2007). Genomic and nongenomic effects of estrogen signaling in human endometrial cells: involvement of the growth factor receptor signaling downstream AKT pathway. Reprod. Sci. 14, 646-654. doi: $10.1177 / 1933719107306872$

Goustard-Langelier, B., Koch, M., Lavialle, M., and Heberden, C. (2013). Rat neural stem cell proliferation and differentiation are durably altered by the in utero polyunsaturated fatty acid supply. J. Nutr. Biochem. 24, 380-387. doi: 10.1016/j.jnutbio.2012.08.001

Gradilla, A. C., Gonzalez, E., Seijo, I., Andres, G., Bischoff, M., GonzalezMendez, L., et al. (2014). Exosomes as Hedgehog carriers in cytoneme-mediated transport and secretion. Nat. Commun. 5, 5649. doi: 10.1038/ncomms6649

Greathouse, K. L., Bredfeldt, T., Everitt, J. I., Lin, K., Berry, T., Kannan, K., et al. (2012). Environmental estrogens differentially engage the histone methyltransferase EZH2 to increase risk of uterine tumorigenesis. Mol. Cancer Res. 10, 546-557. doi: 10.1158/1541-7786.MCR-11-0605

Greathouse, K. L., Cook, J. D., Lin, K., Davis, B. J., Berry, T. D., Bredfeldt, T. G., et al. (2008). Identification of uterine leiomyoma genes developmentally reprogrammed by neonatal exposure to diethylstilbestrol. Reprod. Sci. 15, 765-778. doi: 10.1177/1933719108322440

Halder, S. K., Laknaur, A., Miller, J., Layman, L. C., Diamond, M., and Al-Hendy, A. (2014). Novel MED12 gene somatic mutations in women from the Southern United States with symptomatic uterine fibroids. Mol. Genet. Genomics 290, 505-511. doi: 10.1007/s00438-014-0938-x

Hassan, M., Zhang, D., Salama, S., Hamada, F., Arafa, H., Fouad, H., et al. (2009). Towards fibroid gene therapy: adenovirus-mediated delivery of herpes simplex virus 1 thymidine kinase gene/ganciclovir shrinks uterine leiomyoma in the Eker rat model. Gynecol. Obstet. Invest. 68, 19-32. doi: 10.1159/0002 09675

Hassan, M. H., Salama, S. A., Zhang, D., Arafa, H. M., Hamada, F. M., Fouad, H., et al. (2010). Gene therapy targeting leiomyoma: adenovirus-mediated delivery of dominant-negative estrogen receptor gene shrinks uterine tumors in Eker rat model. Fertil. Steril. 93, 239-250. doi: 10.1016/j.fertnstert.2008. 09.086

Hewitt, S. C., Deroo, B. J., Hansen, K., Collins, J., Grissom, S., Afshari, C. A., et al. (2003). Estrogen receptor-dependent genomic responses in the uterus mirror the biphasic physiological response to estrogen. Mol. Endocrinol. 17, 2070-2083. doi: 10.1210/me.2003-0146

Hofmeister, M. V., Damkier, H. H., Christensen, B. M., Olde, B., Fredrik Leeb-Lundberg, L. M., Fenton, R. A., et al. (2012). 17beta-Estradiol induces nongenomic effects in renal intercalated cells through $G$ protein-coupled estrogen receptor 1. Am. J. Physiol. Renal Physiol. 302, F358-F368. doi: 10.1152/ajprenal.00343.2011 
Ishikawa, H., Ishi, K., Serna, V. A., Kakazu, R., Bulun, S. E., and Kurita, T. (2010). Progesterone is essential for maintenance and growth of uterine leiomyoma. Endocrinology 151, 2433-2442. doi: 10.1210/en.2009-1225

Kahlert, C., and Kalluri, R. (2013). Exosomes in tumor microenvironment influence cancer progression and metastasis. J. Mol. Med. (Berl.) 91, 431-437. doi: 10.1007/s00109-013-1020-6

Kelly, M. J., Qiu, J., and Ronnekleiv, O. K. (2003). Estrogen modulation of G-protein-coupled receptor activation of potassium channels in the central nervous system. Ann. N. Y. Acad. Sci. 1007, 6-16. doi: 10.1196/annals.12 86.001

Kogure, T., Lin, W. L., Yan, I. K., Braconi, C., and Patel, T. (2011). Intercellular nanovesicle-mediated microRNA transfer: a mechanism of environmental modulation of hepatocellular cancer cell growth. Hepatology 54, 1237-1248. doi: 10.1002/hep.24504

Langie, S. A., Achterfeldt, S., Gorniak, J. P., Halley-Hogg, K. J., Oxley, D., van Schooten, F. J., et al. (2013). Maternal folate depletion and high-fat feeding from weaning affects DNA methylation and DNA repair in brain of adult offspring. FASEB J. 27, 3323-3334. doi: 10.1096/fj.12-224121

Lehmann, L., Ferrari, R., Vashisht, A. A., Wohlschlegel, J. A., Kurdistani, S. K., and Carey, M. (2012). Polycomb repressive complex 1 (PRC1) disassembles RNA polymerase II preinitiation complexes. J. Biol. Chem. 287, 35784-35794. doi: 10.1074/jbc.M112.397430

Linder, M. C. (2012). The relationship of copper to DNA damage and damage prevention in humans. Mutat. Res. 733, 83-91. doi: 10.1016/j.mrfmmm.2012.03.010

Luga, V., Zhang, L., Viloria-Petit, A. M., Ogunjimi, A. A., Inanlou, M. R., Chiu, E., et al. (2012). Exosomes mediate stromal mobilization of autocrine Wnt-PCP signaling in breast cancer cell migration. Cell 151, 1542-1556. doi: 10.1016/j.cell.2012.11.024

Makinen, N., Heinonen, H. R., Moore, S., Tomlinson, I. P., van der Spuy, Z. M., and Aaltonen, L. A. (2011a). MED12 exon 2 mutations are common in uterine leiomyomas from South African patients. Oncotarget 2, 966-969. doi: 10.18632/oncotarget. 370

Makinen, N., Mehine, M., Tolvanen, J., Kaasinen, E., Li, Y., Lehtonen, H. J., et al. (2011b). MED12, the mediator complex subunit 12 gene, is mutated at high frequency in uterine leiomyomas. Science 334, 252-255. doi: 10.1126/science. 1208930

Markowski, D. N., Bartnitzke, S., Loning, T., Drieschner, N., Helmke, B. M., and Bullerdiek, J. (2012). MED12 mutations in uterine fibroids-their relationship to cytogenetic subgroups. Int. J. Cancer 131, 1528-1536. doi: 10.1002/ijc.27424

Mas, A., Cervello, I., Gil-Sanchis, C., Faus, A., Ferro, J., Pellicer, A., et al. (2012). Identification and characterization of the human leiomyoma side population as putative tumor-initiating cells. Fertil. Steril. 98, 741.e6-751.e6. doi: 10.1016/j.fertnstert.2012.04.044

Mas, A., Nair, S., Laknaur, A., Simon, C., Diamond, M. P., and Al-Hendy, A. (2015). Stro-1/CD44 as putative human myometrial and fibroid stem cell markers. Fertil. Steril. 104, 225.e3-234.e3. doi: 10.1016/j.fertnstert.2015.04.021

McGuire, M. M., Yatsenko, A., Hoffner, L., Jones, M., Surti, U., and Rajkovic, A. (2012). Whole exome sequencing in a random sample of North American women with leiomyomas identifies MED12 mutations in majority of uterine leiomyomas. PLoS ONE 7:e33251. doi: 10.1371/journal.pone.0033251

Melo, S. A., Luecke, L. B., Kahlert, C., Fernandez, A. F., Gammon, S. T., Kaye, J., et al. (2015). Glypican-1 identifies cancer exosomes and detects early pancreatic cancer. Nature 523, 177-182. doi: 10.1038/nature14581

Melo, S. A., Sugimoto, H., O’Connell, J. T., Kato, N., Villanueva, A., Vidal, A., et al. (2014). Cancer exosomes perform cell-independent microRNA biogenesis and promote tumorigenesis. Cancer Cell 26, 707-721. doi: 10.1016/j.ccell.2014.09.005

Mittal, P., Shin, Y. H., Yatsenko, S. A., Castro, C. A., Surti, U., and Rajkovic, A. (2015). Med12 gain-of-function mutation causes leiomyomas and genomic instability. J. Clin. Invest. 125, 3280-3284. doi: 10.1172/JCI81534

Moller, P., Danielsen, P. H., Jantzen, K., Roursgaard, M., and Loft, S. (2013). Oxidatively damaged DNA in animals exposed to particles. Crit. Rev. Toxicol. 43, 96-118. doi: 10.3109/10408444.2012.756456

Morey, L., and Helin, K. (2010). Polycomb group protein-mediated repression of transcription. Trends Biochem. Sci. 35, 323-332. doi: 10.1016/j.tibs.2010.02.009

Mozzetta, C., Pontis, J., Fritsch, L., Robin, P., Portoso, M., Proux, C., et al. (2014). The histone H3 lysine 9 methyltransferases G9a and GLP regulate polycomb repressive complex 2-mediated gene silencing. Mol. Cell 53, 277-289. doi: 10.1016/j.molcel.2013.12.005

Nawaz, M., Camussi, G., Valadi, H., Nazarenko, I., Ekstrom, K., Wang, X., et al. (2014). The emerging role of extracellular vesicles as biomarkers for urogenital cancers. Nat. Rev. Urol. 11, 688-701. doi: 10.1038/nrurol.2014.301

Ntziachristos, P., Tsirigos, A., Van Vlierberghe, P., Nedjic, J., Trimarchi, T., Flaherty, M. S., et al. (2012). Genetic inactivation of the polycomb repressive complex 2 in T cell acute lymphoblastic leukemia. Nat. Med. 18, 298-301. doi: $10.1038 / \mathrm{nm} .2651$

O’Brien, K., Rani, S., Corcoran, C., Wallace, R., Hughes, L., Friel, A. M., et al. (2013). Exosomes from triple-negative breast cancer cells can transfer phenotypic traits representing their cells of origin to secondary cells. Eur. J. Cancer 49, 1845-1859. doi: 10.1016/j.ejca.2013.01.017

Ono, M., Maruyama, T., Masuda, H., Kajitani, T., Nagashima, T., Arase, T., et al. (2007). Side population in human uterine myometrium displays phenotypic and functional characteristics of myometrial stem cells. Proc. Natl. Acad. Sci. U.S.A. 104, 18700-18705. doi: 10.1073/pnas.0704472104

Ono, M., Qiang, W., Serna, V. A., Yin, P., Coon, J. S. V, Navarro, A., et al. (2012). Role of stem cells in human uterine leiomyoma growth. PLoS ONE 7:e36935. doi: 10.1371/journal.pone.0036935

Ono, M., Yin, P., Navarro, A., Moravek, M. B., Coon, J. S. V, Druschitz, S. A., et al. (2013). Paracrine activation of WNT/beta-catenin pathway in uterine leiomyoma stem cells promotes tumor growth. Proc. Natl. Acad. Sci. U.S.A. 110, 17053-17058. doi: 10.1073/pnas.1313650110

Pan, B. T., Teng, K., Wu, C., Adam, M., and Johnstone, R. M. (1985). Electron microscopic evidence for externalization of the transferrin receptor in vesicular form in sheep reticulocytes. J. Cell Biol. 101, 942-948. doi: 10.1083/jcb.10 1.3 .942

Pasini, D., Cloos, P. A., Walfridsson, J., Olsson, L., Bukowski, J. P., Johansen, J. V., et al. (2010). JARID2 regulates binding of the Polycomb repressive complex 2 to target genes in ES cells. Nature 464, 306-310. doi: 10.1038/nature 08788

Peinado, H., Aleckovic, M., Lavotshkin, S., Matei, I., Costa-Silva, B., MorenoBueno, G., et al. (2012). Melanoma exosomes educate bone marrow progenitor cells toward a pro-metastatic phenotype through MET. Nat. Med. 18, 883-891. doi: $10.1038 / \mathrm{nm} .2753$

Prizant, H., Sen, A., Light, A., Cho, S. N., DeMayo, F. J., Lydon, J. P., et al. (2013). Uterine-specific loss of Tsc2 leads to myometrial tumors in both the uterus and lungs. Mol. Endocrinol. 27, 1403-1414. doi: 10.1210/me.2013-1059

Prossnitz, E. R., and Arterburn, J. B. (2015). International union of basic and clinical pharmacology. XCVII. G protein-coupled estrogen receptor and its pharmacologic modulators. Pharmacol. Rev. 67, 505-540. doi: 10.1124/pr.114.009712

Ringrose, L., and Paro, R. (2007). Polycomb/Trithorax response elements and epigenetic memory of cell identity. Development 134, 223-232. doi: 10.1242/dev.02723

Roma-Rodrigues, C., Fernandes, A. R., and Baptista, P. V. (2014). Exosome in tumour microenvironment: overview of the crosstalk between normal and cancer cells. Biomed Res. Int. 2014, 179486. doi: 10.1155/2014/179486

Sabry, M., and Al-Hendy, A. (2012). Medical treatment of uterine leiomyoma. Reprod. Sci. 19, 339-353. doi: 10.1177/1933719111432867

Schmitges, F. W., Prusty, A. B., Faty, M., Stutzer, A., Lingaraju, G. M., Aiwazian, J., et al. (2011). Histone methylation by PRC2 is inhibited by active chromatin marks. Mol. Cell 42, 330-341. doi: 10.1016/j.molcel.2011.03.025

Schuettengruber, B., Chourrout, D., Vervoort, M., Leblanc, B., and Cavalli, G. (2007). Genome regulation by polycomb and trithorax proteins. Cell 128, 735-745. doi: 10.1016/j.cell.2007.02.009

Schuettengruber, B., Martinez, A. M., Iovino, N., and Cavalli, G. (2011). Trithorax group proteins: switching genes on and keeping them active. Nat. Rev. Mol. Cell Biol. 12, 799-814. doi: 10.1038/nrm3230

Serresi, M., Gargiulo, G., Proost, N., Siteur, B., Cesaroni, M., Koppens, M., et al. (2016). Polycomb repressive complex 2 is a barrier to KRAS-driven inflammation and epithelial-mesenchymal transition in non-small-cell lung cancer. Cancer Cell 29, 17-31. doi: 10.1016/j.ccell.2015.12.006

Shah, M. S., Kim, E., Davidson, L. A., Knight, J. M., Zoh, R. S., Goldsby, J. S., et al. (2016). Comparative effects of diet and carcinogen on microRNA expression in the stem cell niche of the mouse colonic crypt. Biochim. Biophys. Acta 1862, 121-134. doi: 10.1016/j.bbadis.2015.10.012 
Simons, M., and Raposo, G. (2009). Exosomes-vesicular carriers for intercellular communication. Curr. Opin. Cell Biol. 21, 575-581. doi: 10.1016/j.ceb.2009.03.007

Skog, J., Wurdinger, T., van Rijn, S., Meijer, D. H., Gainche, L., Sena-Esteves, M., et al. (2008). Glioblastoma microvesicles transport RNA and proteins that promote tumour growth and provide diagnostic biomarkers. Nat. Cell Biol. 10, 1470-1476. doi: 10.1038/ncb1800

Steffen, P. A., and Ringrose, L. (2014). What are memories made of? How Polycomb and Trithorax proteins mediate epigenetic memory. Nat. Rev. Mol. Cell Biol. 15, 340-356. doi: 10.1038/nrm3789

Tang, W. Y., Newbold, R., Mardilovich, K., Jefferson, W., Cheng, R. Y., Medvedovic, M., et al. (2008). Persistent hypomethylation in the promoter of nucleosomal binding protein 1 (Nsbp1) correlates with overexpression of Nsbp1 in mouse uteri neonatally exposed to diethylstilbestrol or genistein. Endocrinology 149, 5922-5931. doi: 10.1210/en. 2008-0682

Ung, T. H., Madsen, H. J., Hellwinkel, J. E., Lencioni, A. M., and Graner, M. W. (2014). Exosome proteomics reveals transcriptional regulator proteins with potential to mediate downstream pathways. Cancer Sci. 105, 1384-1392. doi: $10.1111 /$ cas. 12534

Vallabhaneni, K. C., Penfornis, P., Dhule, S., Guillonneau, F., Adams, K. V., Mo, Y. Y., et al. (2015). Extracellular vesicles from bone marrow mesenchymal stem/stromal cells transport tumor regulatory microRNA, proteins, and metabolites. Oncotarget 6, 4953-4967. doi: 10.18632/oncotarget.3211

Vermeulen, M., Eberl, H. C., Matarese, F., Marks, H., Denissov, S., Butter, F., et al. (2010). Quantitative interaction proteomics and genome-wide profiling of epigenetic histone marks and their readers. Cell 142, 967-980. doi: 10.1016/j.cell.2010.08.020

Villa, R., Pasini, D., Gutierrez, A., Morey, L., Occhionorelli, M., Vire, E., et al. (2007). Role of the polycomb repressive complex 2 in acute promyelocytic leukemia. Cancer Cell 11, 513-525. doi: 10.1016/j.ccr.2007.04.009

Walker, C. L., and Ho, S. M. (2012). Developmental reprogramming of cancer susceptibility. Nat. Rev. Cancer 12, 479-486. doi: 10.1038/nrc3220

Wang, H., Wang, L., Erdjument-Bromage, H., Vidal, M., Tempst, P., Jones, R. S., et al. (2004). Role of histone H2A ubiquitination in Polycomb silencing. Nature 431, 873-878. doi: 10.1038/nature02985

Wang, M., Zhao, C., Shi, H., Zhang, B., Zhang, L., Zhang, X., et al. (2014). Deregulated microRNAs in gastric cancer tissue-derived mesenchymal stem cells: novel biomarkers and a mechanism for gastric cancer. Br. J. Cancer 110 , 1199-1210. doi: 10.1038/bjc.2014.14

Winuthayanon, W., Hewitt, S. C., and Korach, K. S. (2014). Uterine epithelial cell estrogen receptor alpha-dependent and -independent genomic profiles that underlie estrogen responses in mice. Biol. Reprod. 91, 110. doi: 10.1095/biolreprod.114.120170

Wong, C. W., McNally, C., Nickbarg, E., Komm, B. S., and Cheskis, B. J. (2002). Estrogen receptor-interacting protein that modulates its nongenomic activitycrosstalk with Src/Erk phosphorylation cascade. Proc. Natl. Acad. Sci. U.S.A. 99, 14783-14788. doi: 10.1073/pnas.192569699

Wong, R. L., Wang, Q., Trevino, L. S., Bosland, M. C., Chen, J., Medvedovic, M., et al. (2015). Identification of secretaglobin Scgb2al as a target for developmental reprogramming by BPA in the rat prostate. Epigenetics 10, 127-134. doi: 10.1080/15592294.2015.1009768

Yang, Q., Mas, A., Diamond, M. P., and Al-Hendy, A. (2015a). The mechanism and function of epigenetics in uterine leiomyoma development. Reprod. Sci 23 , 163-175. doi: 10.1177/1933719115584449

Yang, Q., Sun, M., Ramchandran, R., and Raj, J. U. (2015b). IGF-1 signaling in neonatal hypoxia-induced pulmonary hypertension: role of epigenetic regulation. Vascul. Pharmacol. 73, 20-31. doi: 10.1016/j.vph. 2015.04.005

Yean Wong, R. L., Wang, Q., Trevino, L. S., Bosland, M. C., Chen, J., Medvedovic, M., et al. (2015). Identification of Secretaglobin Scgb2al as a target for developmental reprogramming by BPA in the rat prostate. Epigenetics 10, 127-134. doi: 10.1080/15592294.2015.1009768

Yun, M., Wu, J., Workman, J. L., and Li, B. (2011). Readers of histone modifications. Cell Res. 21, 564-578. doi: 10.1038/cr.2011.42

Conflict of Interest Statement: The authors declare that the research was conducted in the absence of any commercial or financial relationships that could be construed as a potential conflict of interest.

Copyright (C) 2016 Yang, Diamond and Al-Hendy. This is an open-access article distributed under the terms of the Creative Commons Attribution License (CC BY). The use, distribution or reproduction in other forums is permitted, provided the original author(s) or licensor are credited and that the original publication in this journal is cited, in accordance with accepted academic practice. No use, distribution or reproduction is permitted which does not comply with these terms. 